\title{
One-Pot Melamine Derived Nitrogen Doped Magnetic Carbon Nanoadsorbents with Enhanced Chromium Removal
}

Yonghai Cao, ${ }^{1,2}$ Jiangnan Huang, ${ }^{1,2}$ Yuhang Li, ${ }^{3}$ Song Qiu, ${ }^{4}$ Jiurong Liu, ${ }^{4}$ Airat Khasanov, Mojammel A Khan, ${ }^{6}$ David P. Young, ${ }^{6}$ Feng Peng, ${ }^{3}$ Dapeng Cao, ${ }^{7}$ Xiangfang Peng, ${ }^{2}$ Kunlun Hong $^{8}$ and Zhanhu Guo ${ }^{1 *}$

${ }^{1}$ Integrated Composites Laboratory (ICL), Department of Chemical and Biomolecular Engineering, University of Tennessee, Knoxville, TN 37996, USA

${ }^{2}$ Laboratory of Polymer Processing Engineering of Ministry of Education, South China University of Technology, Guangzhou, Guangdong 510640, P.R. China

${ }^{3}$ School of Chemistry and Chemical Engineering, South China University of Technology, Guangzhou, Guangdong, 510640, P.R. China

${ }^{4}$ School of Materials Science and Engineering, Shandong University, Jinan, Shandong, 250061, P.R. China

${ }^{5}$ University of North Carolina at Asheville, Asheville, NC 28804, USA

${ }^{6}$ Department of Physics and Astronomy, Louisiana State University, Baton Rouge, LA 70803, USA

${ }^{7}$ Division of Molecular and Materials Simulation Key Lab for Nanomaterials, Beijing University of Chemical Technology, Beijing, 100029, P.R. China

${ }^{8}$ Center for Nanophase Materials Sciences, Oak Ridge National Laboratory, Oak Ridge, TN 37831, USA

*Corresponding authors: Email: zguo10@utk.edu; Tel: +1 (865) 974-2933 (Zhanhu Guo) 
Abstract: Novel nitrogen doped magnetic carbons (NMC), in-situ synthesized through facile pyrolysis-carbonization processes using $\mathrm{Fe}\left(\mathrm{NO}_{3}\right)_{3}$ and melamine as precursors, were demonstrated as excellent nanoadsorbents to remove $\mathrm{Cr}(\mathrm{VI})$ effectively. The achieved removal capacity in both neutral and acidic solution was 29.4 and $2001.4 \mathrm{mg} \mathrm{g}^{-1}$ respectively, much higher than the reported adsorbents so far. The unprecedented high adsorption performance can be attributed to the incorporation of the nitrogen dopant, which increased the negative charge density on the surface of adsorbent and thereby enhanced the interaction betweent the adsorbents and $\mathrm{Cr}(\mathrm{VI})$ ions. The density functional theory (DFT) calculation demonstrated that the nitrogen dopants can decrease the adsorption energy between the $\mathrm{Cr}(\mathrm{VI})$ ions and NMC ($\left.3.456 \mathrm{~kJ} \mathrm{~mol}^{-1}\right)$, lower than the undoped sample $\left(-3.344 \mathrm{~kJ} \mathrm{~mol}^{-1}\right)$, which boosted the adsorption behavior. Chemical rather than physical adsorption was followed for these magnetic nanoadsorbents as revealed from the pseudo-second-order kinetic study. Furthermore, the NMC showed high stability with recycling tests for the $\mathrm{Cr}(\mathrm{VI})$ removal. 


\section{Introduction}

Environmental pollution has become an urgent issue for our society caused by the rapid industrialization [1]. Heavy metal ion $\mathrm{Cr}(\mathrm{VI})$ is a typical contaminant for its wide industrial applications. Herein, it is crucial to remove $\mathrm{Cr}(\mathrm{VI})$ ions from the waste water due to its high toxicity and mobility [2]. Adsorption was considered as a conventional and effective process because of its simple operation without producing by-products, thus avoiding secondary pollution $[3,4]$. Among the reported adsorbents, such as biosorbents, clay minerals, metal phosphates, zeolites, activated carbon, and magnetic carbons [5-12]. Magnetic carbons become popular due to their highly porous structure with easily-controlled chemical properties and magnetization for easy separation $[4,10,11,13-15]$. For example, Lv and coworkers reported a maximum $\mathrm{Cr}(\mathrm{VI})$ removal capacity $\left(q_{\max }\right)$ of $101.0 \mathrm{mg} \mathrm{g}^{-1}(\mathrm{pH}$ is 3 ) for the nano zero-valence iron (ZVI) assembled on magnetic $\mathrm{Fe}_{3} \mathrm{O}_{4} /$ graphene nanocomposites, due to strong adsorption capability of broad graphene sheet/ $\mathrm{Fe}_{3} \mathrm{O}_{4}$ surfaces and the redox reaction between ZVI and $\mathrm{Cr}(\mathrm{VI})$ ions [16]. However, this removal efficiency is still not enough for the heavy metal uptake.

The doping of carbon materials with heteroatoms such as nitrogen and sulfur et al. has attracted considerable attention in the environment remediation [17-21]. Heteroatom dopants can endow adsorbents unique electronic features and rich function groups on the surface, thus change the adsorption efficiency for removing heavy metal ions. Recently, the usage of nitrogen doped carbons as adsorbents in the $\mathrm{Cr}(\mathrm{VI})$ removal received increasing attentions, since the nitrogen atom has higher electronegativity than carbon atom, thus increasing the negative charge density and the amount of higher basicity functionalities on the surface of adsorbent, facilitating the adsorption ability of metal ions [18, 20, 22-24]. For example, Shin and his co-workers reported [19] that the nitrogen doped carbon composites with iron nanoparticles prepared by using pyrrole and ferric chloride as precursors demonstrated great 
active sites for the $\mathrm{Cr}(\mathrm{VI})$ adsorption. The adsorption onto nitrogen doped magnetic carbon composites occurred through a chemical process involving valence forces. The $\mathrm{Cr}$ (III) adsorption capacity of nitrogen doped magnetic carbons was 10 folds higher than that of active carbons [19]. Although great efforts have been made for the nitrogen doped adsorbent to enhance $\mathrm{Cr}(\mathrm{VI})$ removal, two essential problems still remain in the nitrogen doped adsorbents for $\mathrm{Cr}(\mathrm{VI})$ removal: firstly, detailed evidence to confirm the influence of nitrogen dopant on the $\mathrm{Cr}(\mathrm{VI})$ removal efficiency is not reported; secondly, how the $\mathrm{N}$ dopants changing the efficiency of $\mathrm{Cr}(\mathrm{VI})$ removal by modulating the electronic structure of the adsorbent surface is far from understood.

In this work, nitrogen doped magnetic carbons (NMC) with controlled nitrogen doping levels were synthesized through a facile one-step thermal pyrolysis method using melamine as both carbon and nitrogen sources. The influences of $\mathrm{Cr}$ (VI) concentration, adsorbents loading, adsorption time, $\mathrm{pH}$ and the adsorption kinetics were investigated in details. The $\mathrm{Cr}(\mathrm{VI})$ removal performances were studied based on the physical and chemical properties of nanoadsorbents. The relationship between nitrogen doping and $\mathrm{Cr}(\mathrm{VI})$ removal was established. Both kinetics and isothermal analysis were used to disclose the $\mathrm{Cr}(\mathrm{VI})$ removal mechanisms. Theoretical simulation by using density functional theory (DFT) based on the interaction between $\mathrm{Cr}(\mathrm{VI})$ and adsorbent was conducted to understand the enhancement of nitrogen dopant for the $\mathrm{Cr}(\mathrm{VI})$ removal.

\section{Experimental}

\subsection{Materials}

Potassium dichromate $\left(99 \%, \mathrm{~K}_{2} \mathrm{Cr}_{2} \mathrm{O}_{7}\right), 1,5$-diphenylcarbazide $(97 \%$, DPC) and denatured ethanol (92.2\%) were purchased from Alfa Aesar Company. $\mathrm{Fe}\left(\mathrm{NO}_{3}\right)_{3} \cdot 9 \mathrm{H}_{2} \mathrm{O}(99 \%)$, sodium hydroxide $(\mathrm{NaOH}, 99.1 \%)$, sulfuric acid $\left(\mathrm{H}_{2} \mathrm{SO}_{4}, 95 \%\right)$, phosphoric acid $\left(\mathrm{H}_{3} \mathrm{PO}_{4}, 85 \%\right)$, 
melamine (99\%) and glucose (99\%) were obtained from Fisher Scientific. All the chemicals were used as received without any further purification.

\subsection{Synthesis of nitrogen doped magnetic carbon nanoadsorbents}

The nitrogen doped magnetic carbon nanoadsorbents were synthesized as follows. Typically, $6 \mathrm{~g} \mathrm{Fe}\left(\mathrm{NO}_{3}\right)_{3} \cdot 9 \mathrm{H}_{2} \mathrm{O}$ and $3 \mathrm{~g}$ melamine were added into denatured alcohol solvent and then treated under ultrasonication for $2 \mathrm{~h}$ to be intensively mixed. After that, the mixture was dried at $110{ }^{\circ} \mathrm{C}$ overnight. The obtained solid sample was then carbonized at $800{ }^{\circ} \mathrm{C}$ for 2 $\mathrm{h}$ under $\mathrm{N}_{2}$ atmosphere. To control the nitrogen doping levels, glucose was added into mixture to adjust the melamine concentration at $0,33,50,66$ and $100 \mathrm{wt} \%$, which was noted as the NMC-0, NMC-33, NMC-50, NMC-66 and NMC-100, respectively, in the following.

\subsection{Characterizations}

Transmission electron microscope (TEM) images were obtained with a FEI Tecnai G2 12 microscope operated at $100 \mathrm{kV}$. The samplse were prepared by ultrasonically suspending in acetone and depositing several drop of the suspension onto a grid. Scanning electron microscope (SEM) images were obtained with a FEI Quanta 600F electron microscope. X-ray diffraction (XRD) patterns were obtained from a Bruker D8 ADVANCE diffractometer equipped with a rotating anode using $\mathrm{Cu} \mathrm{K} \alpha$ radiation $(40 \mathrm{KV}, 40 \mathrm{~mA}) . \mathrm{X}$-ray photoelectron spectroscopy (XPS) were performed in a Kratos Axis ultra (DLD) spectrometer equipped with an Al Ka X-ray source in ultrahigh vacuum (UHV) $\left(<10^{-10}\right.$ Torr). Brunauer-Emmett-Teller (BET) specific surface areas were measured by $\mathrm{N}_{2}$ adsorption at liquid $\mathrm{N}_{2}$ temperature in an ASAP 2010 analyzer. The magnetic property measurements were conducted in a $2 \mathrm{~T}$ physical

property measurement system (PPMS) by Quantum Design at room temperature. The thermogravimetric analysis (TGA) was carried out on a NETZSCH TGASTA 409 PC analyzer.

\subsection{The Cr(VI) removal performance of NMCs}


Typically, the selected nanoadsorbents were added into the $\mathrm{Cr}(\mathrm{VI})$ solution and treated under ultrasonication for certain time at room temperature. The $\mathrm{Cr}(\mathrm{VI})$ removal efficiency based on the effects of different $\mathrm{Cr}(\mathrm{VI})$ concentration (from 1.0 to $150 \mathrm{mg} \mathrm{L}^{-1}$ ), nanoadsorbents loading (from 0.5 to $5 \mathrm{~g} \mathrm{~L}^{-1}$ ), treatment time (from 2.5 to $10 \mathrm{~min}$ ) and $\mathrm{pH}$ value (from 1.0 to 11 , measured by a pH meter, Vernier Lab Quest with pH-BTA sensor) were studied in details.

\subsection{Computational Simulations}

The adsorption properties were investigated by spin-polarized density functional theory (DFT) calculations with DMol3 package. Exchange-correlation functions were described by GGA/PBE. The electronic basis set was double numerical plus polarization (DNP) set, which was equal to 6-31G** in Gaussian [25]. The "DFT semi-core pseudopots (DSPPs)" method was adopted as the core treatment. The orbital cutoff with $5.0 \AA$ was set for all atoms. To avoid the shortage of handling weak interactions by DFT, the long range dispersion was corrected by the Grimme scheme. The conductor-like screening model (COSMO) with the permittivity of 78.54 (water) was considered to mimic structures encased by the aqueous layer [26]. It is essential to extract a simplified model as the initial structure in DFT calculations. The primitive hexagonal graphene cell was extended to a $(4 \times 4 \times 1)$ supercell with the optimized parameters of $9.84 \AA \times 9.84 \AA \times 25 \AA$, where the extension along c axis represented the elimination of interactions between adjacent layers. The k-point was set to $8 \times 8 \times 1$ after convergence tests. We assumed that $\mathrm{Cr}(\mathrm{VI})$ existed as a form of $\mathrm{CrO}_{4}{ }^{2-}$ cluster with two negative charges. The adsorption energy $\left(\mathrm{E}_{\mathrm{ads}}\right)$ was calculated as the formula below:

$$
\text { Eads }=\mathrm{E}\left(\mathrm{X}^{\cdots} \mathrm{CrO}_{4}{ }^{2-}\right)-\mathrm{E}(\mathrm{X})-\mathrm{E}\left(\mathrm{CrO}_{4}{ }^{2-}\right)
$$

where, $\mathrm{E}\left(\mathrm{X}^{\cdots \cdot \mathrm{CrO}_{4}}{ }^{2-}\right)$ is the energy of the steady adsorption state on different adsorbents; $\mathrm{E}(\mathrm{X})$ is the energy of the isolated adsorbent; $\mathrm{E}\left(\mathrm{CrO}_{4}{ }^{2-}\right)$ is the energy of the isolated adsorbate $\mathrm{CrO}_{4}{ }^{2-}$ cluster. 


\section{Results and discussion}

\subsection{Physical/chemical properties of nitrogen doped magnetic carbons.}

Figures 1a-e display the typical SEM images of magnetic carbons in all the samples prepared at $800{ }^{\circ} \mathrm{C}$ in $\mathrm{N}_{2}$ atmosphere. Large amount of mesoporous carbon are observed and some nanospheres are interconnected but with non-uniform distribution. Figures 1f-j show the TEM images of the NMCs, further revealing the interconnected nanospheres and the core-shell structure in all the samples. The undoped magnetic carbons (NMC-0) displayed relatively uniform particle of $\sim 80 \mathrm{~nm}$ (Figure 1f). However, non-uniform larger core-shell particles from 50 160 $\mathrm{nm}$ were observed after the addition of melamine (Figure $1 \mathrm{~g}$ to $\mathrm{j}$ ), which can be attributed to the aggregation of Fe particles during the pyrolysis and carbonization of melamine. The carbon coating for the NMC-0 was about 3-5 nm, which was also observed in the $\mathrm{Fe}_{3} \mathrm{O}_{4}$ nanocrystals synthesized by the hydrothermal method with glucose as carbon source [27]. For the NMCs, the bouffant structure of carbon layer was observed and attributed to the nitrogen doping. Nitrogen doped carbon nanotubes (NCNTs) with typical bamboo structure in the NMC-100 was also observed (Figure 1k) arising from the high mobility of melamine during the synthesis of NMCs $[28,29]$. The XRD patterns show four kinds of iron state existing in all the samples (Figure 2). The abundance of ZVI nanoparticles was observed, demonstrating that the $\mathrm{Fe}_{3} \mathrm{O}_{4}$ or $\mathrm{Fe}_{2} \mathrm{O}_{3}$ were partially reduced by the glucose or melamine during the calcination process [4], which was also observed in the Mössbauer spectra (Figure S1). The intensity ratio of $\mathrm{Fe}_{3} \mathrm{O}_{4}$ to $\mathrm{ZVI}$ on any NMC was higher than that of the NMC-0, indicating that $\mathrm{Fe}^{3+}$ can be more favorably transformed to the ZVI with the addition of melamine as the precursor. 


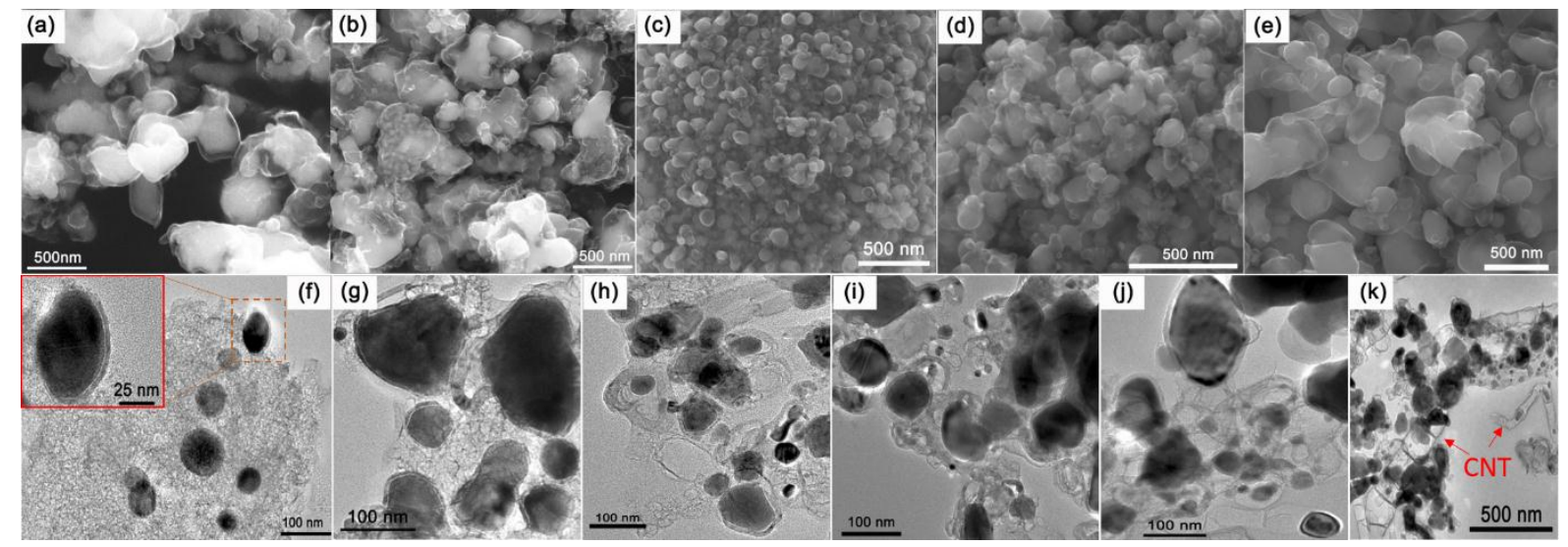

Figure 1. The SEM (a-e) and TEM (f-k) images of magnetic adsorbents: (a and f) for NMC0; (b and g) for NMC-33; (c and h) for NMC-50; (d and i) for NMC-66; (e, j and k) for NMC100.

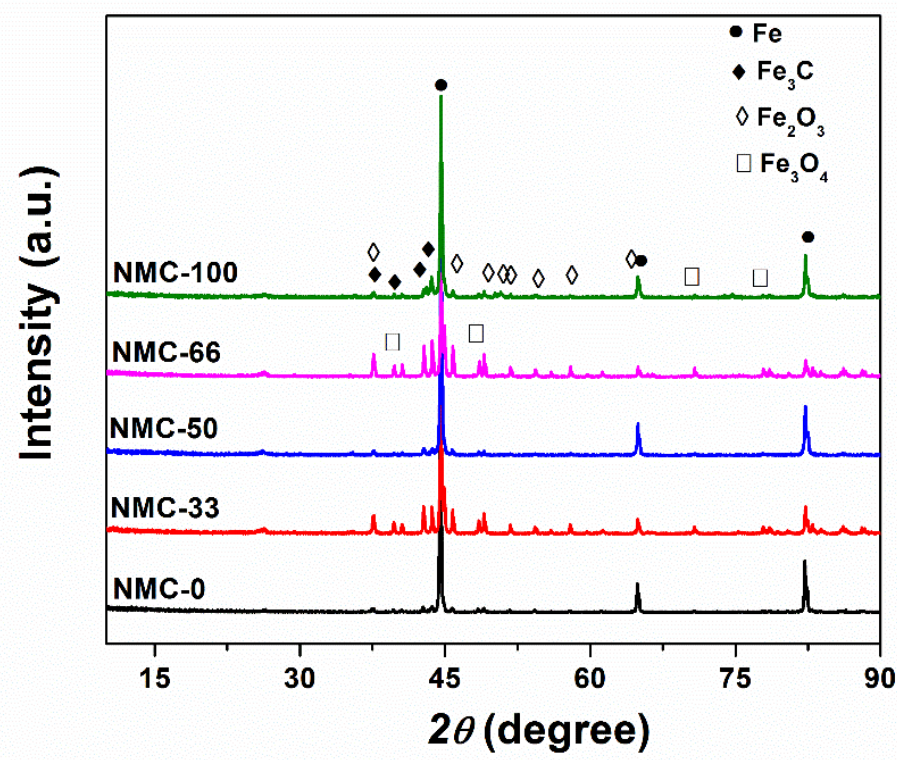

Figure 2. XRD patterns of magnetic adsorbents used in this study.

The nitrogen contents of the doped magnetic carbons were measured by XPS. As shown in Figures S2 and 3, the nitrogen atoms were successfully incorporated in the carbon skeleton. The contents of elements are summarized in Table S1, while Table 1 provides the detailed information about the $\mathrm{N}$ functionalities obtained from the deconvoluted $\mathrm{N}_{1 \mathrm{~s}}$ XPS spectra. With increasing the melamine loading, the $\mathrm{N} /(\mathrm{N}+\mathrm{C})$ atomic ratio increased from 0 to $4.9 \%$. Five nitrogen components were obtained from the spectra, representing pyridinic $\mathrm{N}$, pyrrolic $\mathrm{N}$, 
quaternary N, Noxides and chemisorbed N, respectively [30-34]. The major functionalities of NMCs were pyridinic, pyrrolic and quaternary nitrogens. The pyrrolic nitrogen dramatically increased from 0 to $59.7 \%$ with the addition of $33 \mathrm{wt} \%$ melamine, much higher than pyridinic and quaternary $\mathrm{N}$. When the addition of melamine reached equal to or over $50 \mathrm{wt} \%$, the percentages of pyridinic and quaternary nitrogens increased while pyrrolic nitrogen displayed a slight decrease, demonstrating that the higher melamine loading efficiently led to higher amount of pyridinic and quaternary $\mathrm{N}$.

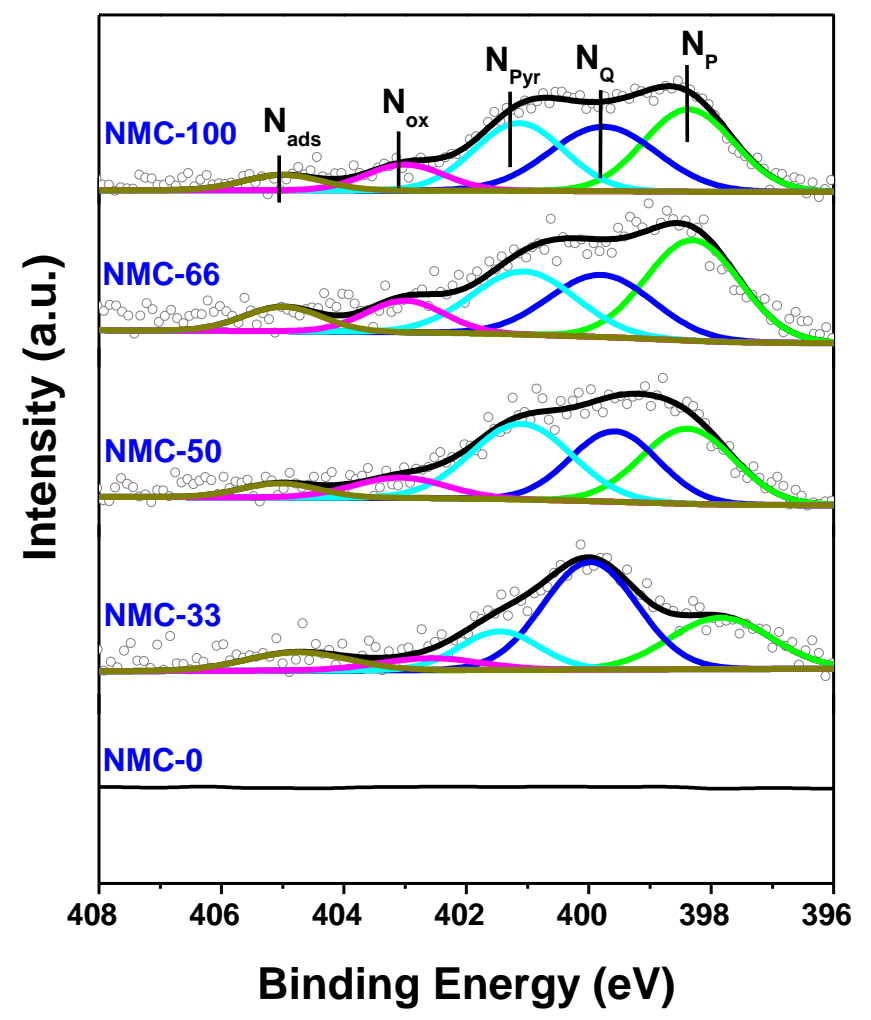

Figure 3. $\mathrm{N}_{1 \mathrm{~s}}$ XPS spectra of the magnetic adsorbents used in this work.

Table 1 Quantitative XPS analysis of the NMCs. NP: pyridinic N, $\mathrm{N}_{\text {Pyr: }}$ pyrrolic $\mathrm{N}, \mathrm{N}_{\mathrm{Q}}$ : quaternary $\mathrm{N}, \mathrm{N}_{\text {ox: Noxides, }} \mathrm{N}_{\text {ads }}$ :chemisorbed $\mathrm{N}$.

\begin{tabular}{ccccccc}
\hline \multirow{2}{*}{ Adsorbents } & $\mathrm{N} /(\mathrm{N}+\mathrm{C})(\%)$ & $\mathrm{N}_{\mathrm{P}}(\%)$ & $\mathrm{N}_{\text {Pyr }}(\%)$ & $\mathrm{N}_{\mathrm{Q}}(\%)$ & $\mathrm{Nox}(\%)$ & $\mathrm{N}_{\text {ads }}(\%)$ \\
& & $398 \mathrm{eV}$ & $400 \mathrm{eV}$ & $401.5 \mathrm{eV}$ & $403 \mathrm{eV}$ & $405 \mathrm{eV}$ \\
\hline NMC-0 & 0 & 0 & 0 & 0 & 0 & 0
\end{tabular}




\begin{tabular}{rrrrrrr}
\hline NMC-33 & 2.1 & 17.4 & 59.7 & 12.1 & 4.8 & 6 \\
NMC-50 & 3.0 & 37.7 & 24.4 & 31.3 & 3.4 & 3.2 \\
NMC-66 & 4.2 & 34.4 & 21.2 & 31.9 & 6.2 & 6.3 \\
NMC-100 & 4.9 & 39.8 & 24.2 & 27.8 & 4.7 & 3.6 \\
\hline
\end{tabular}

Figure 4 shows the Raman spectra of NMCs. According to previous work, the introduction of $\mathrm{N}$ heteroatoms can dramatically change the height and width of $\mathrm{D}$ band, due to the increasing disorder degree of graphene layers with $\mathrm{N}$ doping [34]. Apparently broadened $\mathrm{G}$ and $\mathrm{D}$ bands of these nitrogen doped magnetic carbons can be attributed to the enhanced vibrations from I $\left(1166 \mathrm{~cm}^{-1}\right)$ bands and D' $\left(1600 \mathrm{~cm}^{-1}\right)$ and D' $\left(1490 \mathrm{~cm}^{-1}\right)$ [35]. 5 peaks, i.e. G $\left(1560 \mathrm{~cm}^{-1}\right), \mathrm{D}\left(1320 \mathrm{~cm}^{-1}\right), \mathrm{D}^{\prime}\left(1600 \mathrm{~cm}^{-1}\right), \mathrm{D}^{\prime \prime}\left(1490 \mathrm{~cm}^{-1}\right)$ and I $\left(1166 \mathrm{~cm}^{-1}\right)$ bands, were fitted in the nitrogen doped magnetic carbons. The intensity ratio based on $D$ to $G$ band $\left(\mathrm{I}_{\mathrm{D}} / \mathrm{I}_{\mathrm{G}}\right)$ was used to evaluate the defective degree of NMCs. The NMC-0 displayed low defects degree (0.12) with narrow peak. The $\mathrm{I}_{\mathrm{D}} / \mathrm{I}_{\mathrm{G}}$ of NMC- 0 is 0.12 , demonstrating that this sample has highly graphitized surface [27]. For the nitrogen doped samples, the $\mathrm{I}_{\mathrm{D}} / \mathrm{I}_{\mathrm{G}}$ ratio gradually decreased from 2.44 to 1.25 with increasing the nitrogen content from $2.1 \%$ to $4.9 \%$, totally different from the observation on the NCNT synthesized in the Ar atmosphere [34]. It may be attributed to the decomposition of melamine with the resultant formation of $\mathrm{NH}_{3}$, which can be further decomposed into $\mathrm{H}_{2}$, facilitating the removal of amorphous carbons deposited on the surface of carbons $[34,36]$. 


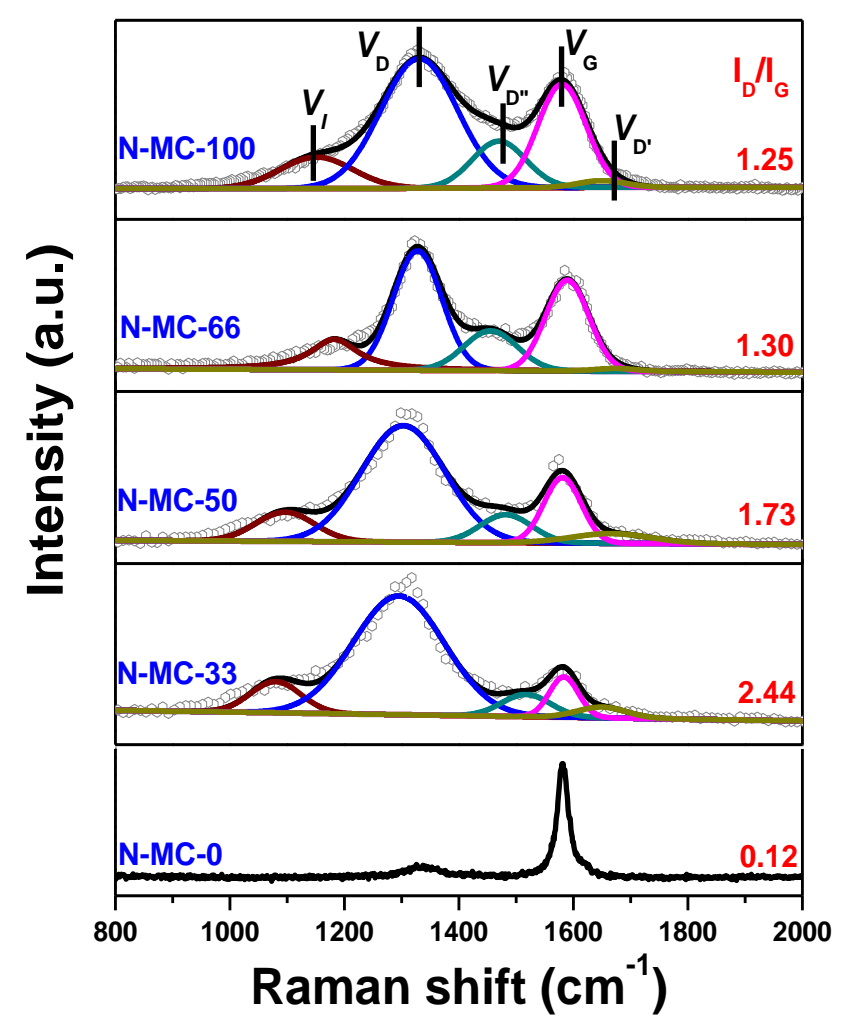

Figure 4. Raman spectra of magnetic adsorbents used in this work.

\section{2 $\mathrm{Cr}(\mathrm{VI})$ removal performance}

The specific surface area and $\mathrm{Cr}(\mathrm{VI})$ removal performance of different adsorbents are summarized in Table 2. The addition of undoped samples (MC) displayed reletively lower efficiency in the $\mathrm{Cr}(\mathrm{VI})$ removal, $30.7 \%$ removal percentage with the $\mathrm{Cr}(\mathrm{VI})$ initial concentration at $20 \mathrm{mg} \mathrm{L}^{-1}$. After nitrogen doped (with $4.9 \% \mathrm{~N}$ content, see Figure 2 and Table 1), the $\mathrm{Cr}(\mathrm{VI})$ removal was greatly boosted to $100 \%$ removal percentage after 10 min ultrasonic treatment, corresponding to a mass removal rate of $3.2 \mathrm{mg} \mathrm{g}^{-1} \mathrm{~min}^{-1}$, which was about 3 times higher than the undoped one. In this study, the mass and surface areas removal rate were directly defined by $\Delta \mathrm{C} /(\Delta \mathrm{t} \cdot \mathrm{m})$ or $\Delta \mathrm{C} /(\Delta \mathrm{t} \cdot \mathrm{S})$, not the Pseudo-second-order model or other models $[11,14]$. Because these models are srongly depended on initial concentration of metal ions [37-39], which is not comparable for the adsorbents under different treatment systems. This removal capacity of NMC was comparable to the state-of-the-art magnetic adsorbent 
reported before, such as magnetic carbon $\left(0.008 \mathrm{mg} \mathrm{g}^{-1} \mathrm{~min}^{-1}\right)$ and reported $\mathrm{N}$ doped porous carbons (Fe and Ni based, 0.063 and $0.004 \mathrm{mg} \mathrm{g}^{-1} \mathrm{~min}^{-1}$, respectively) $[4,18,20]$. There were two possible reasons. The first one is due to the abundent iron particles on the adsorbent surface, Figures 2 and S4. The existing iron particles on the surface played a significant role in the redox reaction with $\mathrm{Cr}(\mathrm{VI})$ ions $[4,11]$. The second reason was due to the NCNTs enclosed with iron oxide synthesized (Figure 1k). The NCNTs could increase the surface areas, and thus created more active sites to adsorb Cr(VI) ions by the NMC. It may be argued that the iron nanoparticles on the surface may be play the signicifant role for the $\operatorname{Cr}(\mathrm{VI})$ removal in the neutral sulotion. Therefore, the NMC adsorbent was washed by concentrated $\mathrm{HCl}$ sulotion for $4 \mathrm{~h}$. Around $82.5 \%$ removal percentage was obtained, indicating that the iron nanoparticles were not the dominat factor for the $\mathrm{Cr}(\mathrm{VI})$ remvoal in the neutral sulotion.

Table 2 The performance comparison of NMCs in the $\mathrm{Cr}(\mathrm{VI})$ removal. $^{[\mathrm{a}]}$

\begin{tabular}{|c|c|c|c|c|c|}
\hline & & $\mathrm{S}_{\mathrm{BET}}[\mathrm{b}]$ & & & \\
\hline Entry & Adsorbents & $\left(\mathrm{m}^{2} \mathrm{~g}^{-1}\right)$ & $\mathrm{X}^{[\mathrm{c}]}(\%)$ & $r_{g}{ }^{[\mathrm{d}]}\left(\mathrm{mg} \mathrm{g}^{-1} \min ^{-1}\right)$ & $r_{s}{ }^{[\mathrm{e}]}\left(\mathrm{mg} \mathrm{m}^{-2} \mathrm{~min}^{-1}\right)$ \\
\hline 1 & $M C^{[f]}$ & 21.7 & 30.7 & 0.980 & 0.041 \\
\hline 2 & $\mathrm{NMC}^{[\mathrm{g}]}$ & 56.2 & 100 & 3.200 & 0.057 \\
\hline 3 & NMC-W ${ }^{[\mathrm{h}]}$ & - & 82.5 & - & - \\
\hline 4 & $\begin{array}{l}\text { Magnetic Carbons } \\
\qquad(\text { Cellulose })^{[i]}\end{array}$ & 111.4 & 100 & 0.008 & $7.000 \times 10^{-4}$ \\
\hline 5 & $\begin{array}{l}\text { N-doped porous } \\
\text { carbon }(\mathrm{Fe})^{[\mathrm{j}]}\end{array}$ & 1136.0 & 92 & 0.063 & $5.586 \times 10^{-5}$ \\
\hline 6 & $\begin{array}{l}\text { N-doped porous } \\
\text { carbon }(\mathrm{Ni})^{[\mathrm{k}]}\end{array}$ & 2148.4 & 100 & 0.004 & $1.862 \times 10^{-6}$ \\
\hline
\end{tabular}


[a] Condition: $[\mathrm{Cr}(\mathrm{VI})]=20 \mathrm{mg} \mathrm{L}{ }^{-1}, \mathrm{pH}=7.0$, adsorbent dosage: $50.0 \mathrm{mg}$, volume: $20 \mathrm{~mL}$, treatment time: $10 \mathrm{~min}$; [b] BET specific surface area, pore size and other dates can be obtained from Figure S3 and Table S2; [c] X: removal percentages; [d] Removal rate of Cr(VI) per gram of adsorbent based on the treatment of $2.5 \mathrm{~min}$. [e] Removal rate of $\mathrm{Cr}(\mathrm{VI})$ per $\mathrm{m}^{2}$ of catalyst surface based on the treatment of $2.5 \mathrm{~min}$; [f] MC is represented as NMC-0; [g] NMC is represented as NMC-100; [h] NMC was washed by concentration $\mathrm{HCl}$ for $4 \mathrm{~h}$; [i] Condition: $[\mathrm{Cr}(\mathrm{VI})]=4 \mathrm{mg} \mathrm{L}^{-1}, \mathrm{pH}=7.0$, adsorbent dosage: $50.0 \mathrm{mg}$, volume: $20 \mathrm{~mL}$, treatment time: 10 min (ref. [4]); [j] Condition: [Cr (VI)] $=31.73 \mathrm{mg} \mathrm{L}^{-1}, \mathrm{pH}=3$, adsorbent dosage: $2 \mathrm{~g} \mathrm{~L}^{-1}$, treatment time: $10 \mathrm{~min}$ (ref. [18]); [k] Condition: $[\mathrm{Cr}(\mathrm{VI})]=6 \mathrm{mg} \mathrm{L}^{-1}, \mathrm{pH}=2.5$, adsorbent dosage: $0.05 \mathrm{~g} \mathrm{~L}^{-1}$, treatment time: $30 \mathrm{~min}$ (ref. [20]).

Based on the aforementioned discussion, NMC is superior for the $\mathrm{Cr}(\mathrm{VI})$ removal. Herein, the NMC was used as the adsorbent to investigate the effect of initial $\mathrm{Cr}(\mathrm{VI})$ concentration, adsorbent dose, treat time and $\mathrm{pH}$ on the $\mathrm{Cr}(\mathrm{VI})$ removal efficiency. Figure 5a shows the $\mathrm{Cr}(\mathrm{VI})$ removal performance with different $\mathrm{Cr}(\mathrm{VI})$ concentrations by $\mathrm{NMC}$ in the neutral solution. $\mathrm{Up}$ to $20 \mathrm{mg} \mathrm{L}^{-1}, \mathrm{Cr}(\mathrm{VI})$ could be completely removed by $2.5 \mathrm{~g} \mathrm{~L}^{-1} \mathrm{NMC}$ in $10 \mathrm{~min}$. This high $\mathrm{Cr}(\mathrm{VI})$ removal rate can be attributed to the abundant active sites on the NMC surface. The removal activity decreased with further increasing the $\mathrm{Cr}(\mathrm{VI})$ concentration from $40 \mathrm{mg} \mathrm{L}^{-1}$, mainly as a result of the limited active adsorption sites covered by $\mathrm{Cr}(\mathrm{VI})$ ions on the adsorbent surface [4]. The removal capacity increased along with increasing the initial $\mathrm{Cr}(\mathrm{VI})$ concentration, indicating that the active sites were gradually saturated with the adsorbed $\mathrm{Cr}(\mathrm{VI})$ ions [11]. And also the increasing driving force provided by the higher initial $\mathrm{Cr}(\mathrm{VI})$ concentration on the NMC surface enabled more collisions between the $\mathrm{Cr}(\mathrm{VI})$ ions and active sites, and therefore resulted in a greater amount of $\mathrm{Cr}(\mathrm{VI})$ ions being adsorbed or reacted on the surface of NMC [20]. Figure 5b shows the effect of adsorbent concentration on the $\mathrm{Cr}(\mathrm{VI})$ removal. The increase of adsorbent loading can efficiently enhance the $\mathrm{Cr}(\mathrm{VI})$ removal, which 
can be attributed to more active sites for the adsorption of $\mathrm{Cr}(\mathrm{VI})$ ions on the surface of adsorbent. The decrease of $q_{e}$ demonstrated that most active sites were saturated [11]. A higher $\mathrm{Cr}(\mathrm{VI})$ removal efficiency was observed for the NMC (Figure 5c) with almost $90 \% \mathrm{Cr}(\mathrm{VI})$ removal percentages with $7.5 \mathrm{mg} \mathrm{g}^{-1}\left(q_{e}\right)$ within $2.5 \mathrm{~min}$, demonstrating that the NMC could be used as excellent adsorbents for the adsorption of $\mathrm{Cr}(\mathrm{VI})$ ions with high removal capacity and fast removal rate.

(a)

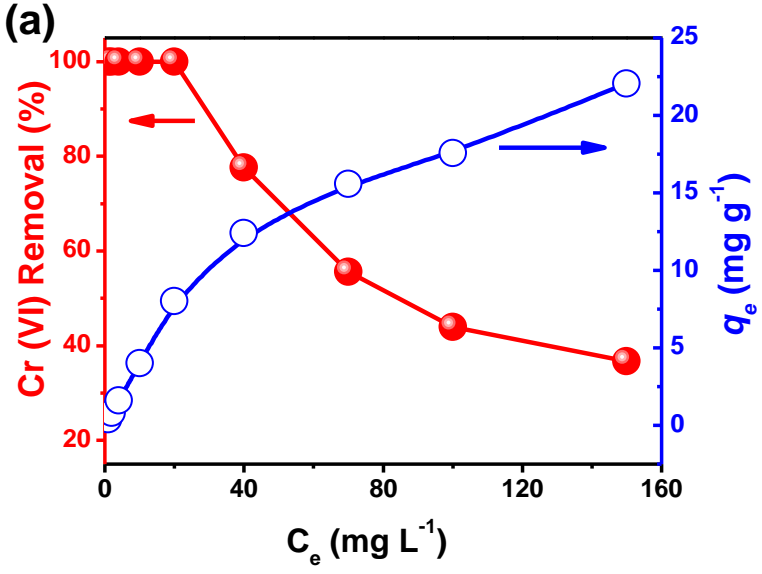

(c)

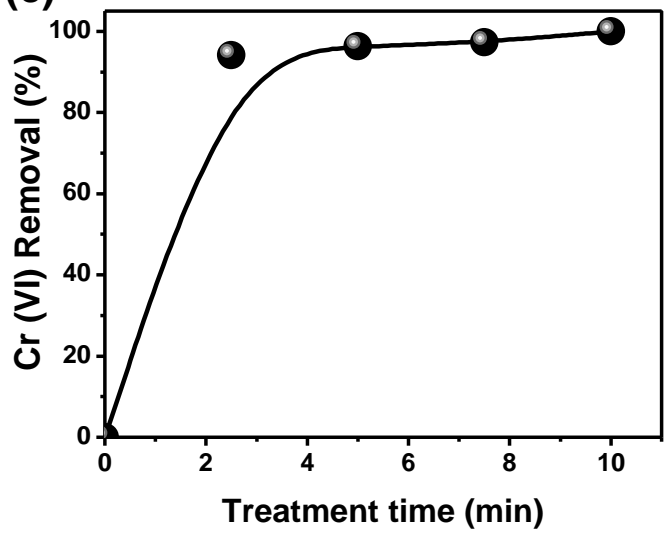

(b)

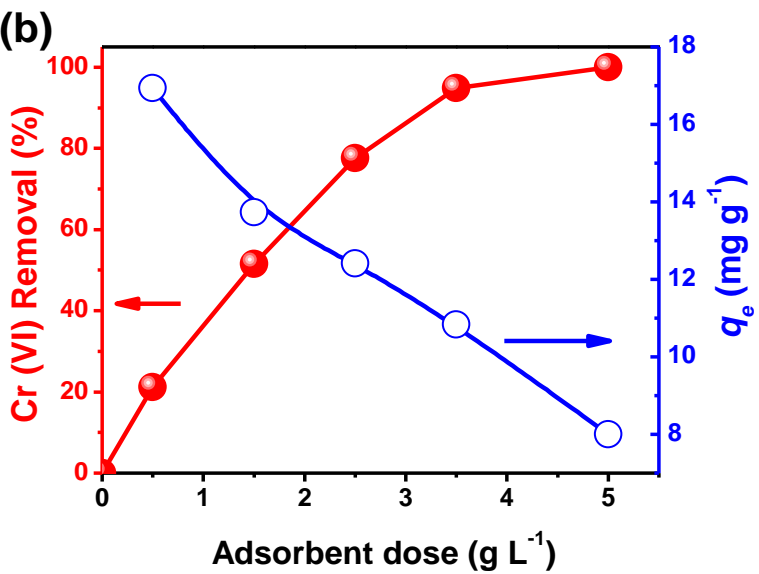

(d)

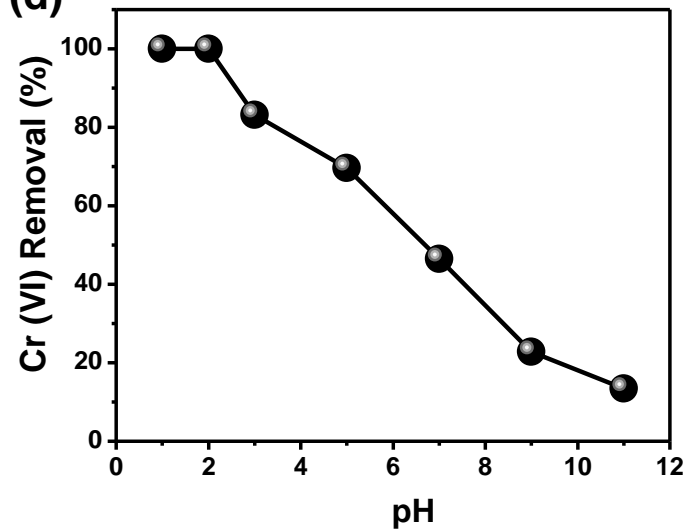

Figure 5. (a) effect of initial $\mathrm{Cr}(\mathrm{VI})$ concentration on $\mathrm{Cr}(\mathrm{VI})$ removal performance (adsorbent dosage: $50.0 \mathrm{mg}$, volume: $20 \mathrm{~mL}$, pH: 7.0, treating time: $10 \mathrm{~min}$ ) and the transformed rate plot $\mathrm{C}_{\mathrm{e}}$ vs. $\mathrm{q}_{\mathrm{e}}$ (open circle with blue color); (b) $\mathrm{Cr}(\mathrm{VI})$ removal performance of different adsorbent concentrations $\left([\mathrm{Cr}(\mathrm{VI})]=40 \mathrm{mg} \mathrm{L}^{-1}, \mathrm{pH}=7.0\right.$, volume: $20 \mathrm{~mL}$, treating time: $\left.10 \mathrm{~min}\right)$ and the transformed rate plot $\mathrm{C}_{\mathrm{e}} \mathrm{vs}$. $\mathrm{q}_{\mathrm{e}}$ (open circle with blue color); (c) $\mathrm{Cr}(\mathrm{VI})$ removal performance with different treatment time $\left([\mathrm{Cr}(\mathrm{VI})]=40 \mathrm{mg} \mathrm{L}^{-1}, \mathrm{pH}=7\right.$, adsorbent dosage: $50.0 \mathrm{mg}$, 
volume: $20 \mathrm{~mL}$ ); (d) Effect of solution $\mathrm{pH}$ on the $\mathrm{Cr}(\mathrm{VI})$ removal efficiency of NMC. ([Cr(VI)] = $1000 \mathrm{mg} \mathrm{L}^{-1}$, adsorbent dosage: $50.0 \mathrm{mg}$, volume: $20 \mathrm{~mL}$, treating time: $10 \mathrm{~min}$ ).

It has been shown that $\mathrm{pH}$ plays an important role on the heavy metal ion removal [4]. In this work, NMC was added into solutions with an initial Cr(VI) concentration of $1000 \mathrm{mg} \mathrm{L}^{-1}$ and a wide range of $\mathrm{pH}$ from 1 to 11 (Figure 5d). The removal percentage of $\mathrm{Cr}(\mathrm{VI})$ increased from $46.5 \%$ to $100 \%$ when the $\mathrm{pH}$ changed from 7.0 to 1.0 , demonstrating the $\mathrm{Cr}(\mathrm{VI})$ removal enhancement with a strong acidic medium. When the $\mathrm{pH}$ value increased from 7 to 11 , a negative effect on $\mathrm{Cr}(\mathrm{VI})$ removal was observed (from $46.5 \%$ to $13.4 \%$ ). $\mathrm{Cr}(\mathrm{VI})$ ions could exist in several anionic forms (i.e., $\mathrm{Cr}_{2} \mathrm{O}_{7}^{2-}, \mathrm{HCr}_{2} \mathrm{O}_{7}^{-}, \mathrm{HCrO}_{4}^{-}$and $\mathrm{CrO}_{4}{ }^{2-}$ ) in aqueous solutions $[4,11]$. At a lower $\mathrm{pH}(<6.8)$, the main species is $\mathrm{HCrO}_{4}^{-}$, while $\mathrm{CrO}_{4}{ }^{2-}$ will be the dominating specie when $\mathrm{pH}$ is above 6.8 [11]. In addition, the surface chemistry of adsorbent plays a key role in the $\mathrm{Cr}(\mathrm{VI})$ removal efficiency. As reported by Zhang et al., the $\mathrm{pH}$ at point of zero charge $\left(\mathrm{pH}_{\mathrm{pzc}}\right)$ of $\mathrm{NMC}$ is about 3.6, much lower than the regular carbon materials, for instance, granular activated carbon (6.3), natural corncob (6.2), and untreated coffee husks (4.5) [20, 4042]. The low $\mathrm{pH}_{\mathrm{pzc}}$ was beneficial for the negative charge on the surface of NMC and thus enhanced the adsorption of $\mathrm{Cr}(\mathrm{VI})$ ions $[18,20]$. With increasing the $\mathrm{pH}$, the $\mathrm{Cr}(\mathrm{VI})$ removal percentage gradually decreased, arising from the adsorption competition between the highly concentrated $\mathrm{OH}^{-}$ions and $\mathrm{Cr}(\mathrm{VI})$ ions. In addition, the electrostatic repulsion between the $\mathrm{Cr}(\mathrm{VI})$ ions and the active sites on the surface of $\mathrm{NMC}$ would increase when the $\mathrm{pH}$ was over $\mathrm{pH}_{\mathrm{pzc}}$ of $\mathrm{NMC}$ [20], indicating more difficult for the $\mathrm{NMC}$ to adsorb $\mathrm{Cr}(\mathrm{VI})$ ions in the alkaline solution.

Two kinetic models (i.e., pseudo-first-order and pseudo-second-order models) were employed in this work (Figure S5). The adsorption process was found to fit better with a pseudo-second-order model with a correlation more than 0.99 , indicating a chemical adsorption for the NMC adsorbents [43]. The adsorption isotherms fitted by Langmuir and Freundlich 
models of $\mathrm{Cr}(\mathrm{VI})$ ions on the surface of NMC were obtained in neutral and acidic solutions (Figure S6 and Table S3). The calculated maximum $\mathrm{Cr}(\mathrm{VI})$ removal capacity based on the Langmuir model was about 29.46 and $2001.4 \mathrm{mg} \mathrm{g}^{-1}$ in neutral and acidic solutions, much higher than the reported adsorbents, and displayed competitive performance to the adsorbent (such as nano Fe, activated carbon and $\alpha-\mathrm{Fe}_{2} \mathrm{O}_{3}$ ) in the acidic circumstance (see Table 3) [23, 44, 45]. The NMC in this work displayed higher $q_{\max }$ and $q_{s}$ than the reported nitrogen doped magnetic carbons even though our NMCs had lower surface areas, which could be attributed to more active sites created on the surface after nitrogen doping [18, 20, 46].

Table 3 Comparison of $\mathrm{Cr}$ ( VI ) removal capacities with other adsorbents.

\begin{tabular}{|c|c|c|c|c|c|c|}
\hline & Adsorbent & $\begin{array}{c}S_{B E T} \\
\left(\mathrm{~m}^{2} \mathrm{~g}^{-1}\right)\end{array}$ & $\begin{array}{c}q_{\max }{ }^{[\mathrm{a}]} \\
\left(\mathrm{mg} \mathrm{g}^{-1}\right)\end{array}$ & $\begin{array}{c}q_{s}{ }^{[\mathrm{b}]} \\
\left(\mathrm{mg} \mathrm{m}^{-2}\right)\end{array}$ & $\mathrm{pH}$ & Refs. \\
\hline \multirow{4}{*}{$\begin{array}{c}\text { Neutral } \\
\text { solutio } \\
n\end{array}$} & NMC-100 & 56.2 & 29.46 & 0.52 & 7 & This work \\
\hline & $\begin{array}{l}\text { Magnetic Carbon } \\
\text { (Cellulose) }\end{array}$ & 111.4 & 15.3 & 0.14 & 7 & {$[4]$} \\
\hline & MN (Cotton fabric) & 91.1 & 3.74 & 0.04 & 7 & {$[11]$} \\
\hline & $\begin{array}{c}\text { Graphene } \\
\text { nanocomposites }\end{array}$ & 42.1 & 1.03 & 0.02 & 7 & {$[47]$} \\
\hline \multirow{9}{*}{$\begin{array}{c}\text { Acidic } \\
\text { solutio } \\
\mathrm{n}\end{array}$} & NMC-100 & 56.2 & 2001.4 & 35.61 & 1 & This work \\
\hline & $\begin{array}{l}\text { N-doped porous carbon } \\
(\mathrm{Fe})\end{array}$ & 1136.0 & 16 & 0.02 & 3 & {$[18]$} \\
\hline & $\begin{array}{l}\mathrm{N} \text {-doped porous carbon } \\
(\mathrm{Ni})\end{array}$ & 2148.4 & 96.27 & 0.04 & 2.5 & {$[20]$} \\
\hline & $\begin{array}{l}\text { Melamine-resorcinol- } \\
\text { terephthaldehyde (MRT) }\end{array}$ & 628.0 & 102.88 & 0.16 & 3 & {$[23]$} \\
\hline & Micron Fe & - & $2.16-1.33$ & - & 3 & {$[48]$} \\
\hline & Nano Fe & 35 & $\begin{array}{l}64.16- \\
67.67\end{array}$ & $1.83-1.93$ & 3 & {$[48]$} \\
\hline & $\alpha-\mathrm{Fe}_{2} \mathrm{O}_{3}$ & 40.0 & 4.47 & 0.11 & 3 & {$[44]$} \\
\hline & Activated carbon & $\mathrm{n} / \mathrm{a}$ & 112.36 & $\mathrm{n} / \mathrm{a}$ & 1 & {$[45]$} \\
\hline & $\mathrm{MnO}_{2} / \mathrm{Fe}_{3} \mathrm{O}_{4} / \mathrm{o}-\mathrm{WCNTs}$ & 92.0 & 186.9 & 2.03 & 2 & [49] \\
\hline
\end{tabular}

[a] $q_{\max }$ is obtained through the Langmuir isotherm; [b] $q_{s}$ is represented as the adsorption capacity per $\mathrm{m}^{2}$ of catalyst surface.

\subsection{Reusability}

The reusability of adsorbent is an important consideration for practical applications. Figure 6 shows the stability of the NMC in the $\mathrm{Cr}(\mathrm{VI})$ removal for five runs. After each run, 
the recycled adsorbent was washed by deionized water and $0.01 \mathrm{~mol} \mathrm{~L}^{-1} \mathrm{NaOH}$ solution repeated several times for the adsorbent regeneration $[49,50]$. After that, the adsorbent was then dried at $80{ }^{\circ} \mathrm{C}$ overnight. The results demonstrated that the adsorbents displayed only a slight decline in the $\mathrm{Cr}(\mathrm{VI})$ removal when used 5 times. About $90 \%$ removal percentage of $\mathrm{Cr}(\mathrm{VI})$ and $7.5 \mathrm{mg} \mathrm{g}^{-1}$ removal capacity for the 5th cycle were obtained, demonstrating an excellent stability for the $\mathrm{Cr}(\mathrm{VI})$ removal over NMC under mild conditions. The declined activity can be attributed to the consumption of zero-valence iron and the blocked active sites by the adsorbed $\mathrm{Cr}(\mathrm{VI})$ and $\mathrm{Cr}(\mathrm{III})$ ions (Figure 7a) [18]. showed The obtained similar $\mathrm{I}_{\mathrm{D}} / \mathrm{I}_{\mathrm{G}}$ values in the Raman spectra before and after usage (Figure 7b) indicate that the adsorbent was very stable in natural solution for the $\mathrm{Cr}(\mathrm{VI})$ removal. Additionally, the saturation magnetizations of fresh and used adsorbents were 130.7 and $125.8 \mathrm{emu}^{-1}$, respectively, and thus could be easily separated by the permanent magnet from the treated solution after usage (Figure 7c). The slight decrease of adsorbent magnetizaiton was possibly caused by the comsuption of the ZVI, forming the iron oxide and $\mathrm{Cr}$ (III) ions on the surface of adsorbent [4]. The Fe $2 p$ XPS spectra of the adsorbent before and after used were shown in Figure $7 d$. Four main peaks, i.e., the ZVI $(706.9 \mathrm{eV}), \mathrm{Fe}^{2+}(709.8 \mathrm{eV})$ and $\mathrm{Fe}^{3+}(711.8 \mathrm{eV}$ and $724.7 \mathrm{eV})$, were deconvoluted. Compared with the fresh adsorbent, almost no ZVI particles were observed after 5 times recycles, indicating that the ZVI was consumed during the treatment process. These results demonstrated that the NMC displayed an excellent structrure and performance stability under the current condition. 


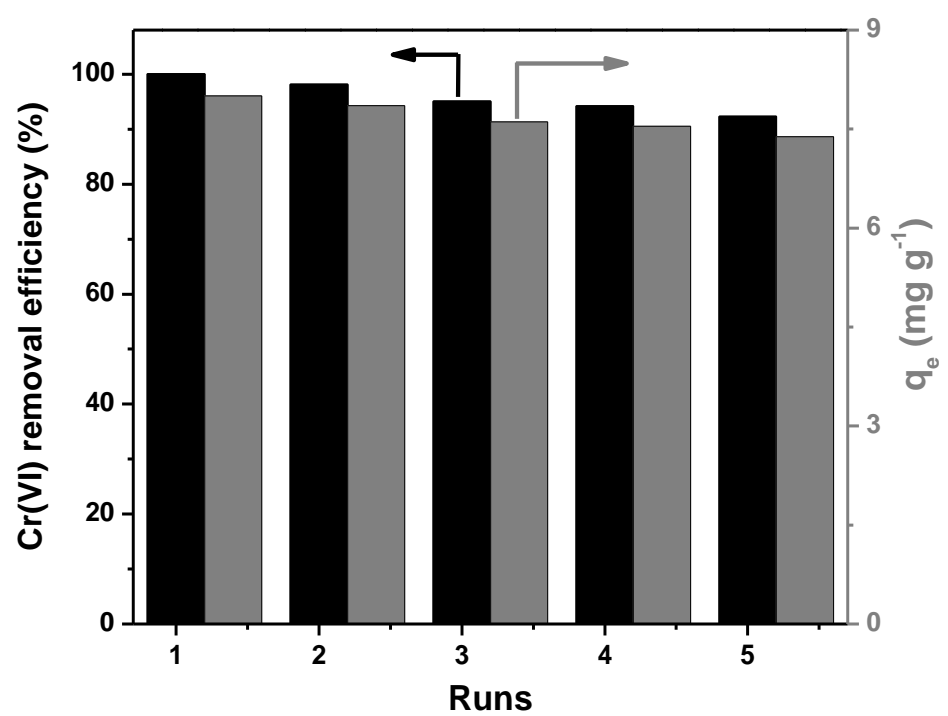

Figure 6. The reusability of the NMC for the $\mathrm{Cr}(\mathrm{VI})$ removal in this work, condition: $[\mathrm{Cr}$ $(\mathrm{VI})]=20 \mathrm{mg} \mathrm{L}^{-1}, \mathrm{pH}=7.0$, adsorbent dosage: $50.0 \mathrm{mg}$, volume: $20 \mathrm{~mL}$, treatment time: 10 min.
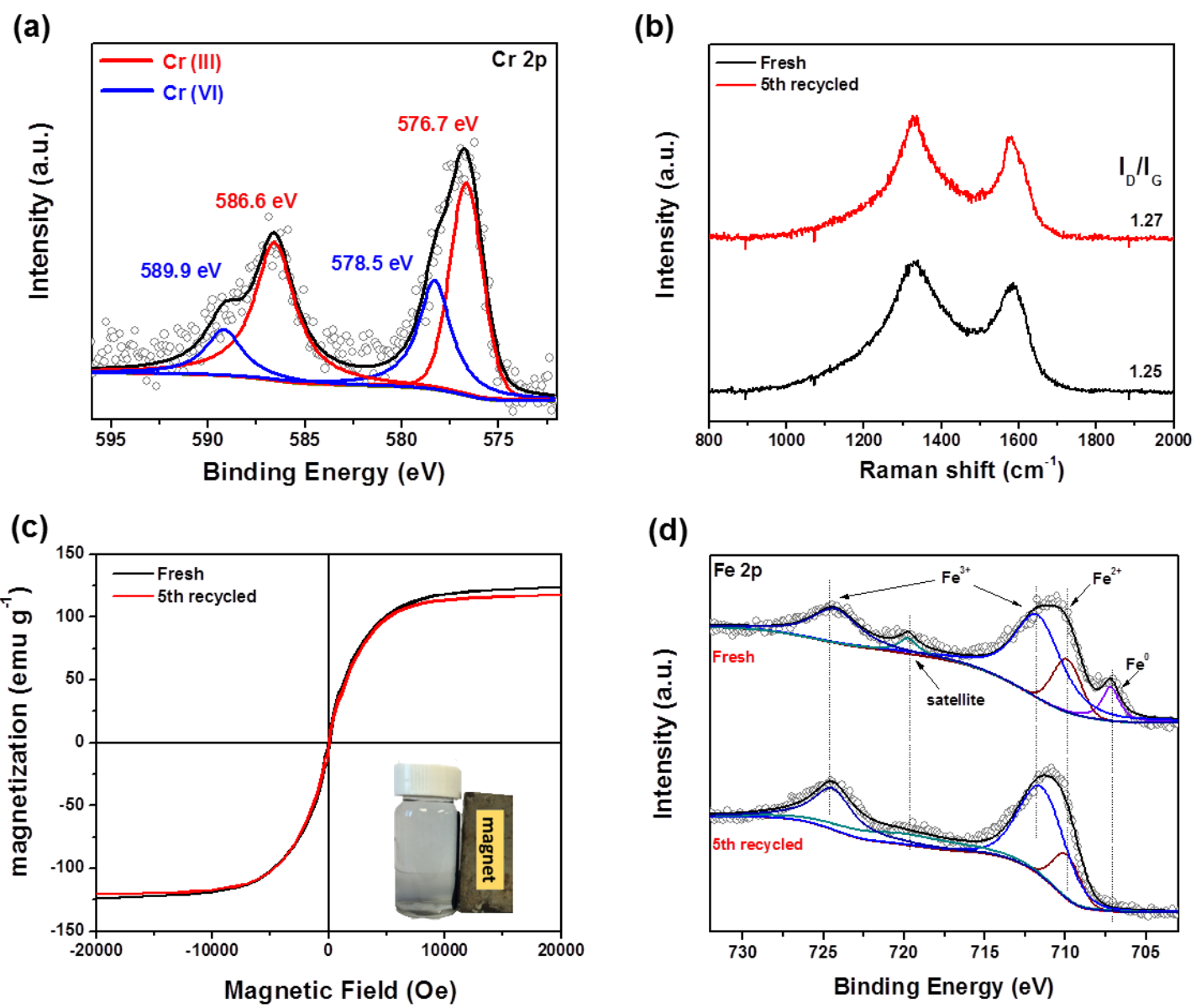
Figure 7. (a) Raman spectral, (b) magnetization and (c) Fe 2p XPS spectra of the fresh and 5th recycled samples, (d) Cr 2p XPS result of the 5th recycled samples.

\subsection{Removal mechanism of NMC}

According to earlier results, magnetic carbons can efficiently remove $\mathrm{Cr}(\mathrm{VI})$ ions through two key pathways: adsorption and redox reaction [47]. The redox reaction between the ZVI and $\mathrm{Cr}(\mathrm{VI})$ took place following equation (3):[4]

$$
\mathrm{Cr}_{2} \mathrm{O}_{7}^{2-}+2 \mathrm{Fe}+7 \mathrm{H}_{2} \mathrm{O} \rightarrow 2 \mathrm{Cr}^{3+}+2 \mathrm{Fe}^{3+}+14 \mathrm{OH}^{-}
$$

In this study, the ZVI also existed on the surface of samples (Figure 2). From the XPS result, similar Fe contents were obtained on the MC and NMC (Table S1). Nevertheless, much higher activity was observed over nitrogen doped adsorbents (Table 2). Neverthless, there is rare work focusing on the structure and heteroatoms functionality on the surface of adsorbent. In order to investigate the relationship between the $\mathrm{Cr}(\mathrm{VI})$ removal and physical/chemical properties of adsorbents in details, the NMC with different nitrogen contents and other physical properties were prepared to investigate the structure-performance relationship for the $\mathrm{Cr}(\mathrm{VI})$ removal.

The role of nitrogen content on the $\mathrm{Cr}(\mathrm{VI})$ removal was investigated to obtain an intrinsic mechanism for the $\mathrm{Cr}(\mathrm{VI})$ removal. The nitrogen content in magnetic carbons was tuned by the glucose adding. The Cr(VI) removal performance with different NMCs are shown in the Figure 8. The nitrogen doping apparently enhanced the $\mathrm{Cr}(\mathrm{VI})$ removal performance. In this work, with the increase of melamine, the sole nitrogen source, the $\mathrm{Cr}(\mathrm{VI})$ removal percentages gradually increased (Figure 8a). The highest efficiency for the $\mathrm{Cr}(\mathrm{VI})$ removal was obtained on the NMC-100, displaying $100 \%$ removal for the $20 \mathrm{mg} \mathrm{L}^{-1} \mathrm{Cr}(\mathrm{VI})$ concentration within 10 min. Moreover, larger BET specific surface area and bigger pore size not only benefited the adsorption of $\mathrm{Cr}(\mathrm{VI})$ ions (See Figure S7), but also improved the $\mathrm{Cr}(\mathrm{VI})$ diffusion into the internal pores and thereby facilitated the redox reaction with the electron donors (i.e., ZVI and 
$\mathrm{Cr}(\mathrm{VI})$ ions) [4]. Furthermore, in this study, the defect of NMCs was observed not the vital factor in the Cr(VI) removal (Figure S8). To exclude the effect of the structure dependence, the removal rate normalized by mass weight and surface area were applied to represent the $\mathrm{Cr}(\mathrm{VI})$ removal efficiency. From the Figure $8 \mathrm{~b}$, the removal rates based on the mass and specific surface areas also increased with increasing the nitrogen dopant. The highest removal activity, $0.057 \mathrm{mg} \mathrm{m}^{-2} \mathrm{~min}^{-1}$, was obtained over the adsorbent synthesized from melamine (NMC-100). These results evidently showed that the removal activity of NMCs could be modulated by the nitrogen doping level.
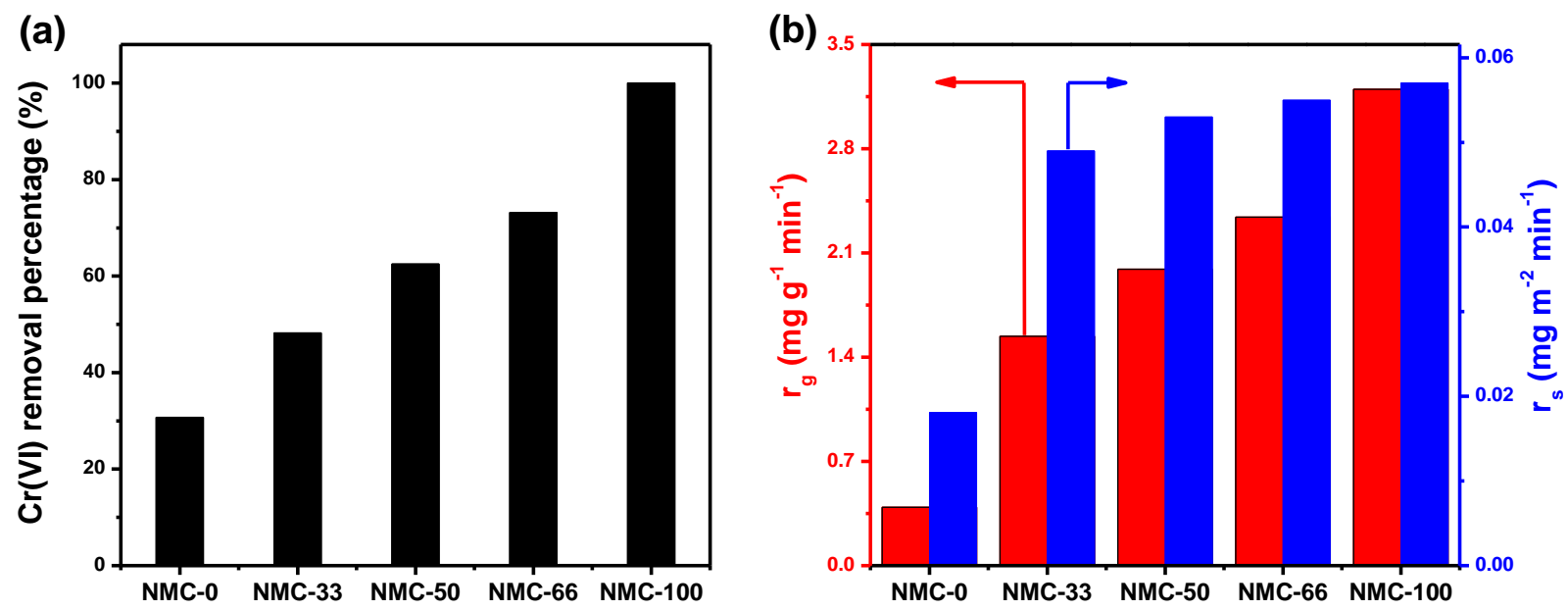

Figure 8. [a] Performance of different adsorbents on the $\mathrm{Cr}(\mathrm{VI})$ removal, condition: [Cr (VI)] $=20 \mathrm{mg} \mathrm{L}^{-1}, \mathrm{pH}=7.0$, adsorbent dosage: $50.0 \mathrm{mg}$, volume: $20 \mathrm{~mL}$, treatment time: $10 \mathrm{~min}$; [b] Removal rate of $\mathrm{Cr}(\mathrm{VI})$ per gram and per $\mathrm{m}^{2}$ of catalyst surface of adsorbent based on the treatment within $2.5 \mathrm{~min}$.

The specific type of the nitrogen functionalities on the surface of NMC, such as pyridinic and quaternary nitrogen, are usually considered as the active sites to adsorb the intermediate species [51, 52]. Therefore, it is necessary to obtain the effect of specific nitrogen functionalities for the $\mathrm{Cr}(\mathrm{VI})$ removal. Figure 9 shows the dependences of surface-areanormalized activity on the nitrogen gross content and functionalities content in NMCs. The results demonstrated that the nitrogen dopant acted as active sites on the surface and could 
directly enhance the $\mathrm{Cr}(\mathrm{VI})$ removal. This indicated that the negative charge of nitrogen dopant was much helpful for the adsorption of $\mathrm{Cr}(\mathrm{VI})$ ions, displaying a positive effect of nitrogen heteroatoms on the $\mathrm{Cr}(\mathrm{VI})$ removal $[18,20]$. Therefore, it can be concluded that the $\mathrm{Cr}(\mathrm{VI})$ removal activity can be efficiently adjusted by the nitrogen dopant.
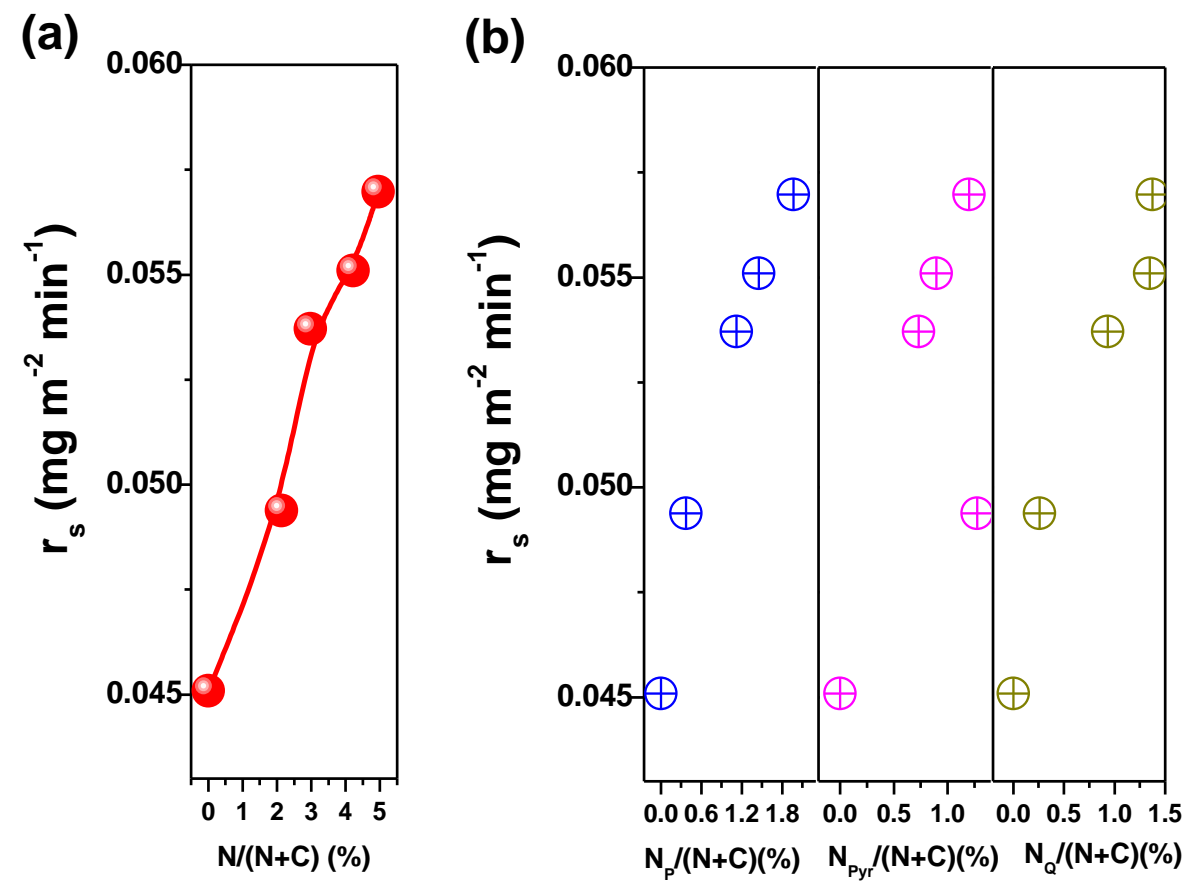

Figure 9. Dependences of $\mathrm{Cr}(\mathrm{VI})$ removal rate on the amounts of nitrogen: (a) gross $\mathrm{N}$ content; (b) $\mathrm{N}$ functionalities, $\mathrm{N}_{\mathrm{p}}$ : pyridinic group; $\mathrm{N}_{\text {pyr: }}$ : pyrrolic group; $\mathrm{N}_{\mathrm{Q}}$ : graphitic $\mathrm{N}$ group.

To further understand the important role of adsorbent in the heavy metal removal, the DFT simulation was usually utilized to faciliate further undertanding the interaction between the adsorbent and metal ions [53, 54]. In this work, the MC and NMC displayed huge differences on the $\mathrm{Cr}(\mathrm{VI})$ removal and $\mathrm{N}$ dopant was proved to greatly enhance the $\mathrm{Cr}(\mathrm{VI})$ removal performance. Since the nitrogen dopant can change the surface charge density of nanocarbons, we believed that the attraction between the $\mathrm{CrO}_{4}{ }^{2-}$ and adsorbent can be adjusted after the addition of nitrogen dopant. As repoted that $\mathrm{CrO}_{4}{ }^{2-}$ is the main chromium species in the nuetral solution, herein we selected $\mathrm{CrO}_{4}{ }^{2-}$ species represented as the $\mathrm{Cr}(\mathrm{VI})$ ion $[4,11]$. As shown in 
the Figure 10, the $\mathrm{CrO}_{4}{ }^{2-}$ ions was attracted by the adsorbent due to the electrostatic attraction [4]. And then the $\mathrm{CrO}_{4}{ }^{2-}$ reacted with the $\mathrm{ZVI}$ particles through the redox reaction to produce $\mathrm{Cr}(\mathrm{III})$ ions, whcih was also adsorbed on the surface of adsorbent. The interaction between the adsorbents and metal ions played a significant role on enhancing the $\mathrm{Cr}(\mathrm{VI})$ removal efficiency. The DFT results demonstrated that the adsorption energy for the MC and NMC to adsorb $\mathrm{CrO}_{4}{ }^{2-}$ ions was -3.344 and $-3.456 \mathrm{~kJ} \mathrm{~mol}^{-1}$, respectively, demonstrating that the NMC could adsorb the $\mathrm{CrO}_{4}{ }^{2-}$ ions more easily, consistent with our experimental results (Table 2), revealling that $\mathrm{N}$ doping efficiently facilitated the $\mathrm{Cr}(\mathrm{VI})$ removal by the enhanced interaction between metal ions and carbons.

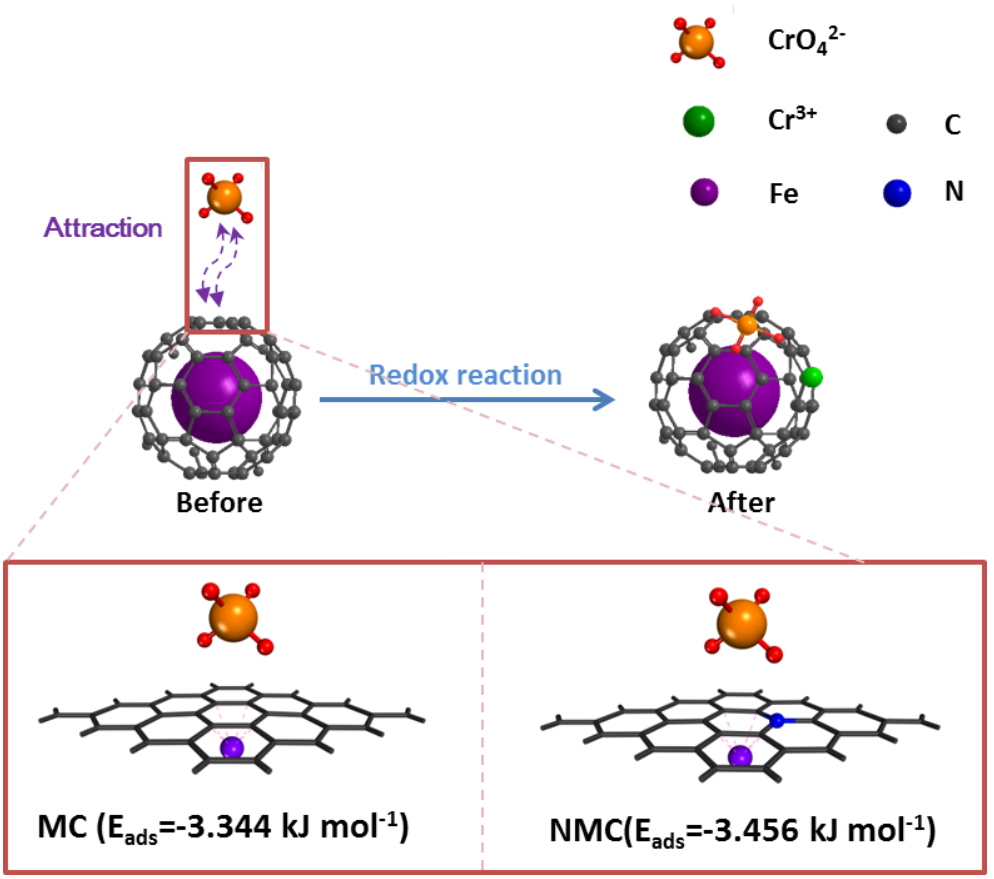

Figure 10. Proposed adsorption mechanism of magnetic carbons for the $\mathrm{Cr}(\mathrm{VI})$ removal.

\section{Conclusions}

In this work, NMCs synthesized from melamine have demonstrated as unique adsorbents for the $\mathrm{Cr}(\mathrm{VI})$ removal. The $\mathrm{N}$ dopant can modulate the physical/chemistry property of the adsorbents, such as morphology, defects and surface functionality. A systematic investigation on the influences of the $\mathrm{N}$ content, $\mathrm{pH}, \mathrm{Cr}(\mathrm{VI})$ concentration, treatment time and adsorbent 
dose showed that excellent $\mathrm{Cr}(\mathrm{VI})$ removal performance can be attributed to the nitrogen dopant and the ZVI. The $\mathrm{N}$ dopant on the carbon surface can increase its negative charge density and then enhance the ability for the $\mathrm{Cr}(\mathrm{VI})$ removal rate $\left(3.20 \mathrm{mg} \mathrm{g}^{-1} \mathrm{~min}^{-1}\right)$, much higher than the undoped sample $\left(0.98 \mathrm{mg} \mathrm{g}^{-1} \mathrm{~min}^{-1}\right)$. The $\mathrm{Cr}(\mathrm{VI})$ removal capacity of 29.4 and $2001.4 \mathrm{mg} \mathrm{g}^{-1}$ for the neutral and acidic solution, respectively, was obtained over NMC. The DFT theoretical calculation results also revealed a lower adsorption energy $\left(-3.456 \mathrm{~kJ} \mathrm{~mol}^{-1}\right)$ between the NMC and metal ions than the undoped one $\left(-3.344 \mathrm{~kJ} \mathrm{~mol}^{-1}\right)$, evidencing that the nitrogen dopant could enhance the interation between the metal ions and adsorbent. In addition, the NMC with outstanding recyclability have demonstraed excellent potential adsorbent for serving as nanoadorbents.

\section{Supporting Information Available.}

Additional characterization, adsorption kinetic study and more discussion can be found in Supporting Information.

\section{Acknowledgments}

This project was financially supported from the start-up fund of University of Tennessee, National Natural Science Foundation of China (Nos. 21503082, 51573063 and 21174044), Guangdong Provincial National Science Foundation (Nos. 2014 A030310447 and S2013020013855), Fundamental Research Funds for the Central Universities of China (No. 2015ZM048), Guangdong Science and Technology Planning Project (Nos. 2014B010104004, 201604010013 and 2013B090600126) and National Basic Research Development Program 973 in China (NO. 2012CB025902). J. Huang acknowledges the support from China Scholarship Council (CSC) program. Part of the characterizations including the TGA, TEM 
and XRD were carried out at the Center for Nanophase Materials Sciences, which is a DOE Office of Science User Facility. 


\section{References}

[1] P. Suksabye, A. Nakajima, P. Thiravetyan, Y. Baba, W. Nakbanpote. Mechanism of Cr(VI) adsorption by coir pith studied by ESR and adsorption kinetic. J. Hazard. Mater. 2009; 161 (23): 1103-8.

[2] L.C. Hsu, S.L. Wang, Y.C. Lin, M.K. Wang, P.N. Chiang, J.C. Liu, et al. Cr(VI) Removal on Fungal Biomass of Neurospora crassa: the Importance of Dissolved Organic Carbons Derived from the Biomass to Cr(VI) Reduction. Environ. Sci. Tech. 2010; 44 (16): 6202-8.

[3] Z. Wei, R. Xing, X. Zhang, S. Liu, H. Yu, P. Li. Facile Template-Free Fabrication of Hollow Nestlike $\alpha$-Fe2O3 Nanostructures for Water Treatment. ACS Appl. Mat. Interfaces 2013; 5 (3): 598-604.

[4] B. Qiu, H. Gu, X. Yan, J. Guo, Y. Wang, D. Sun, et al. Cellulose derived magnetic mesoporous carbon nanocomposites with enhanced hexavalent chromium removal. J. Mater. Chem. A 2014; 2 (41): 17454-62.

[5] B. Krishna, D. Murty, B.J. Prakash. Surfactant-modified clay as adsorbent for chromate. Appl. Clay Sci. 2001; 20 (1): 65-71.

[6] A.M. Yusof, N.A.N.N. Malek. Removal of $\mathrm{Cr}(\mathrm{VI})$ and $\mathrm{As}(\mathrm{V})$ from aqueous solutions by HDTMA-modified zeolite Y. J. Hazard. Mater. 2009; 162 (2): 1019-24.

[7] D. Kratochvil, P. Pimentel, B. Volesky. Removal of trivalent and hexavalent chromium by seaweed biosorbent. Environ. Sci. Tech. 1998; 32 (18): 2693-8.

[8] A. Szabó, D. Gournis, M.A. Karakassides, D. Petridis. Clay-Aminopropylsiloxane Compositions. Chem. Mater. 1998; 10 (2): 639-45.

[9] H. Tamai, T. Kakii, Y. Hirota, T. Kumamoto, H. Yasuda. Synthesis of Extremely Large Mesoporous Activated Carbon and Its Unique Adsorption for Giant Molecules. Chem. Mater. 1996; 8 (2): 454-62.

[10] B. Qiu, Y. Wang, D. Sun, Q. Wang, X. Zhang, B.L. Weeks, et al. Cr(VI) removal by magnetic carbon nanocomposites derived from cellulose at different carbonization temperatures. J. Mater. Chem. A 2015; 3 (18): 9817-25.

[11] J.H. Zhu, H.B. Gu, J. Guo, M.J. Chen, H.G. Wei, Z.P. Luo, et al. Mesoporous magnetic carbon nanocomposite fabrics for highly efficient $\mathrm{Cr}(\mathrm{VI})$ removal. J. Mater. Chem. A 2014; 2 (7): 2256-65.

[12] I.L. Shashkova, A.I. Rat'ko, N.V. Kitikova. Removal of heavy metal ions from aqueous solutions by alkaline-earth metal phosphates. Colloids Surf., A 1999; 160 (3): 207-15.

[13] C.X. Xu, B. Qiu, H.B. Gu, X.R. Yang, H.G. Wei, X.H. Huang, et al. Synergistic Interactions between Activated Carbon Fabrics and Toxic Hexavalent Chromium. ECS J. Solid State Sci. Technol. 2014; 3 (3): M1-M9.

[14] J.H. Zhu, S.Y. Wei, M.J. Chen, H.B. Gu, S.B. Rapole, S. Pallavkar, et al. Magnetic nanocomposites for environmental remediation. Adv. Powder Technol. 2013; 24 (2): 459-67.

[15] J.H. Zhu, R. Sadu, S.Y. Wei, D.H. Chen, N. Haldolaarachchige, Z.P. Luo, et al. Magnetic Graphene Nanoplatelet Composites toward Arsenic Removal. ECS J. Solid State Sci. Technol. 2012; 1 (1): M1-M5.

[16] X. Lv, X. Xue, G. Jiang, D. Wu, T. Sheng, H. Zhou, et al. Nanoscale Zero-Valent Iron (nZVI) assembled on magnetic Fe3O4/graphene for Chromium (VI) removal from aqueous solution. J. Colloid Interface Sci. 2014; 417: 51-9.

[17] F. Cai, X. Liu, S. Liu, H. Liu, Y. Huang. A simple one-pot synthesis of highly fluorescent nitrogen-doped graphene quantum dots for the detection of $\mathrm{Cr}(\mathrm{VI})$ in aqueous media. RSC Adv. 2014; 4 (94): 52016-22.

[18] Y. Li, S. Zhu, Q. Liu, Z. Chen, J. Gu, C. Zhu, et al. N-doped porous carbon with magnetic particles formed in situ for enhanced Cr(VI) removal. Water Res. 2013; 47 (12): 4188-97. 
[19] K.-Y. Shin, J.-Y. Hong, J. Jang. Heavy metal ion adsorption behavior in nitrogen-doped magnetic carbon nanoparticles: Isotherms and kinetic study. J. Hazard. Mater. 2011; 190 (1-3): $36-44$.

[20] S. Zhang, X. Wang, J. Li, T. Wen, J. Xu, X. Wang. Efficient removal of a typical dye and $\mathrm{Cr}(\mathrm{VI})$ reduction using N-doped magnetic porous carbon. RSC Adv. 2014; 4 (108): 63110-7.

[21] G. Zhao, L. Jiang, Y. He, J. Li, H. Dong, X. Wang, et al. Sulfonated graphene for persistent aromatic pollutant management. Adv. Mater. 2011; 23 (34): 3959-63.

[22] A.L. Allred, E.G. Rochow. A scale of electronegativity based on electrostatic force. J. Inorg. Nucl. Chem. 1958; 5 (4): 264-8.

[23] J. Wang, S. Xu, Y. Wang, R. Cai, C. Lv, W. Qiao, et al. Controllable synthesis of hierarchical mesoporous/microporous nitrogen-rich polymer networks for $\mathrm{CO}_{2}$ and $\mathrm{Cr}(\mathrm{VI})$ ion adsorption. RSC Adv. 2014; 4 (31): 16224-32.

[24] F. Lin, Y. Wang, Z. Lin. One-pot synthesis of nitrogen-enriched carbon spheres for hexavalent chromium removal from aqueous solution. RSC Adv. 2016; 6 (39): 33055-62.

[25] H. Kruse, L. Goerigk, S. Grimme. Why the Standard B3LYP/6-31G* Model Chemistry Should Not Be Used in DFT Calculations of Molecular Thermochemistry: Understanding and Correcting the Problem. J. Org. Chem. 2012; 77 (23): 10824-34.

[26] R. Zhang, L. Ling, Z. Li, B. Wang. Solvent effects on Cu2O(l 11 1) surface properties and CO adsorption on $\mathrm{Cu} 2 \mathrm{O}\left(\begin{array}{lll}1 & 1 & 1\end{array}\right)$ surface: A DFT study. Appl. Catal. A: Gen 2011; 400 (1-2): $142-7$.

[27] N. Zhao, S. Wu, C. He, Z. Wang, C. Shi, E. Liu, et al. One-pot synthesis of uniform Fe3O4 nanocrystals encapsulated in interconnected carbon nanospheres for superior lithium storage capability. Carbon 2013; 57: 130-8.

[28] G. Zhong, H. Wang, H. Yu, F. Peng. Nitrogen doped carbon nanotubes with encapsulated ferric carbide as excellent electrocatalyst for oxygen reduction reaction in acid and alkaline media. J. Power Sources 2015; 286 (0): 495-503.

[29] J.-S. Li, S.-L. Li, Y.-J. Tang, M. Han, Z.-H. Dai, J.-C. Bao, et al. Nitrogen-doped Fe/Fe3C@graphitic layer/carbon nanotube hybrids derived from MOFs: efficient bifunctional electrocatalysts for ORR and OER. Chem. Commun. 2015; 51 (13): 2710-3.

[30] J.R. Pels, F. Kapteijn, J.A. Moulijn, Q. Zhu, K.M. Thomas. Evolution of nitrogen functionalities in carbonaceous materials during pyrolysis. Carbon 1995; 33 (11): 1641-53.

[31] B. Stöhr, H.P. Boehm, R. Schlögl. Enhancement of the catalytic activity of activated carbons in oxidation reactions by thermal treatment with ammonia or hydrogen cyanide and observation of a superoxide species as a possible intermediate. Carbon 1991; 29 (6): 707-20.

[32] Z. Chen, D. Higgins, H.S. Tao, R.S. Hsu, Z.W. Chen. Highly Active Nitrogen-Doped Carbon Nanotubes for Oxygen Reduction Reaction in Fuel Cell Applications. J. Phys. Chem. C 2009; 113 (49): 21008-13.

[33] S. Van Dommele, A. Romero-Izquirdo, R. Brydson, K.P. de Jong, J.H. Bitter. Tuning nitrogen functionalities in catalytically grown nitrogen-containing carbon nanotubes. Carbon 2008; 46 (1): 138-48.

[34] Y. Cao, H. Yu, J. Tan, F. Peng, H. Wang, J. Li, et al. Nitrogen-, phosphorous-and borondoped carbon nanotubes as catalysts for the aerobic oxidation of cyclohexane. Carbon 2013; 57: 433-42.

[35] S. Maldonado, S. Morin, K.J. Stevenson. Structure, composition, and chemical reactivity of carbon nanotubes by selective nitrogen doping. Carbon 2006; 44 (8): 1429-37.

[36] D. Price, Y. Liu, G.J. Milnes, R. Hull, B.K. Kandola, A.R. Horrocks. An investigation into the mechanism of flame retardancy and smoke suppression by melamine in flexible polyurethane foam. Fire Mater. 2002; 26 (4-5): 201-6.

[37] M.J. Alowitz, M.M. Scherer. Kinetics of Nitrate, Nitrite, and Cr(VI) Reduction by Iron Metal. Environ. Sci. Tech. 2002; 36 (3): 299-306. 
[38] R.-S. Juang, M.-L. Chen. Application of the Elovich Equation to the Kinetics of Metal Sorption with Solvent-Impregnated Resins. Ind. Eng. Chem. Res. 1997; 36 (3): 813-20.

[39] S.K. Srivastava, R. Tyagi, N. Pant. Adsorption of heavy metal ions on carbonaceous material developed from the waste slurry generated in local fertilizer plants. Water Res. 1989; 23 (9): 1161-5.

[40] T. Karanfil, J.E. Kilduff. Role of Granular Activated Carbon Surface Chemistry on the Adsorption of Organic Compounds. 1. Priority Pollutants. Environ. Sci. Tech. 1999; 33 (18): 3217-24.

[41] L. Billon, V. Meric, A. Castetbon, J. Francois, J. Desbrieres. Removal of copper ions from water of boilers by a modified natural based, corncobs. J. Appl. Polym. Sci. 2006; 102 (5): 4637-45.

[42] L.C.A. Oliveira, R.V.R.A. Rios, J.D. Fabris, V. Garg, K. Sapag, R.M. Lago. Activated carbon/iron oxide magnetic composites for the adsorption of contaminants in water. Carbon 2002; 40 (12): 2177-83.

[43] J.H. Zhu, H.B. Gu, S.B. Rapole, Z.P. Luo, S. Pallavkar, N. Haldolaarachchige, et al. Looped carbon capturing and environmental remediation: case study of magnetic polypropylene nanocomposites. RSC Adv. 2012; 2 (11): 4844-56.

[44] L.S. Zhong, J.S. Hu, H.P. Liang, A.M. Cao, W.G. Song, L.J. Wan. Self-Assembled 3D Flowerlike Iron Oxide Nanostructures and Their Application in Water Treatment. Adv. Mater. 2006; 18 (18): 2426-31.

[45] A. El-Sikaily, A.E. Nemr, A. Khaled, O. Abdelwehab. Removal of toxic chromium from wastewater using green alga Ulva lactuca and its activated carbon. J. Hazard. Mater. 2007; 148 (1-2): 216-28.

[46] A. Modi, B. Bhaduri, N. Verma. Facile One-Step Synthesis of Nitrogen-Doped Carbon Nanofibers for the Removal of Potentially Toxic Metals from Water. Ind. Eng. Chem. Res. 2015; 54 (18): 5172-8.

[47] J.H. Zhu, S.Y. Wei, H.B. Gu, S.B. Rapole, Q. Wang, Z.P. Luo, et al. One-Pot Synthesis of Magnetic Graphene Nanocomposites Decorated with Core@ Double-shell Nanoparticles for Fast Chromium Removal. Environ. Sci. Tech. 2012; 46 (2): 977-85.

[48] J. Cao, W.-X. Zhang. Stabilization of chromium ore processing residue (COPR) with nanoscale iron particles. J. Hazard. Mater. 2006; 132 (2-3): 213-9.

[49] C. Luo, Z. Tian, B. Yang, L. Zhang, S. Yan. Manganese dioxide/iron oxide/acid Oxidized multi-walled carbon nanotube magnetic nanocomposite for enhanced hexavalent chromium removal. Chem. Eng. J. 2013; 234: 256-65.

[50] J. Wang, K. Pan, Q. He, B. Cao. Polyacrylonitrile/polypyrrole core/shell nanofiber mat for the removal of hexavalent chromium from aqueous solution. J. Hazard. Mater. 2013; 244245: 121-9.

[51] Y. Gao, G. Hu, J. Zhong, Z. Shi, Y. Zhu, D.S. Su, et al. Nitrogen-doped sp2-hybridized carbon as a superior catalyst for selective oxidation. Angew. Chem. Int. Ed. 2013; 52 (7): 210913.

[52] C.L. Chen, J. Zhang, B.S. Zhang, C.L. Yu, F. Peng, D.S. Su. Revealing the enhanced catalytic activity of nitrogen-doped carbon nanotubes for oxidative dehydrogenation of propane. Chem. Commun. 2013; 49 (74): 8151-3.

[53] H. Valencia, A. Gil, G. Frapper. Trends in the Adsorption of 3d Transition Metal Atoms onto Graphene and Nanotube Surfaces: A DFT Study and Molecular Orbital Analysis. J. Phys. Chem. C 2010; 114 (33): 14141-53.

[54] A. Ishii, M. Yamamoto, H. Asano, K. Fujiwara. DFT calculation for adatom adsorption on graphene sheet as a prototype of carbon nanotube functionalization. J. Phys: Conf. Ser. 2008; 100 (5): 052087. 